\title{
BMJ Open Determinants of COVID-19-related knowledge and preventive behaviours among students in reopened secondary schools: cross-sectional study
}

\author{
Simegnew Handebo (D), Asmamaw Adugna, Ayenew Kassie (D) , Kegnie Shitu
}

To cite: Handebo S, Adugna A, Kassie A, et al. Determinants of COVID-19-related knowledge and preventive behaviours among students in reopened secondary schools: crosssectional study. BMJ Open 2021;11:e050189. doi:10.1136/ bmjopen-2021-050189

- Prepublication history and additional online supplemental material for this paper are available online. To view these files, please visit the journal online (http://dx.doi.org/10. 1136/bmjopen-2021-050189).

Received 13 February 2021 Revised 13 April 2021 Accepted 13 April 2021
Check for updates

(c) Author(s) (or their employer(s)) 2021. Re-use permitted under CC BY-NC. No commercial re-use. See rights and permissions. Published by BMJ.

Department of Health Education and Behavioral Sciences, Institute of public health,

College of Medicine and Health Sciences, University of Gondar, Gondar, Ethiopia

Correspondence to Simegnew Handebo; hsimegnew@yahoo.com

\section{ABSTRACT}

Purpose In Ethiopia, more than 26 million students have been out of the classroom for nearly 9 months. On 18 September, the Ethiopian Minister of Health advised the Parliament the possibility of reopening schools provided certain conditions were met. Schools are currently reopening in the country for the first time since March 2020.

Objective This study assessed the knowledge and preventive health behaviours toward COVID-19 and associated factors among secondary school students.

Design, setting, participants and outcome measures An institution-based cross-sectional study was conducted from October to December 2020 in Gondar city, Northwest Ethiopia. A total of 370 secondary school students were included. Bivariable and multivariable ordinal logistic regression model were fitted to identify the predictors of knowledge about COVID-19. Simple and multiple linear regression analysis were done to identify factors associated with preventive behaviour. A $p<0.05$ was used to declare statistical significance.

Results Only one-fourth $(23.5 \%, 95 \% \mathrm{Cl} 19.5 \%$ to $28.1 \%)$ of the participants had a good knowledge about COVID-19. The mean score of preventive behaviour was $22.8 \pm \mathrm{SD}$ 6.2. Marital status, religion, father education, living arrangement and sources of information were significantly associated with knowledge about COVID-19. Being female and using health professionals as source of information increased the engagement in preventive behaviours. On the other hand, student whose father employed in nongovernmental organisation and other jobs had decreased engagement in preventive health behaviours.

Conclusion Significant number of the students had inadequate knowledge about COVID-19 and poorly engaged in COVID-19 preventive behaviour. Thus, it is suggested to include and disseminate about COVID-19 in related academic sessions, using school clubs and minimedias. The sources of COVID-19-related information need to strengthen the dissemination of tailored, credible and timely message to enhance the knowledge and engagement of the students in preventive behaviours.

\section{BACKGROUND}

The novel SARS-CoV-2 or COVID-19 was first reported in December 2019, in Wuhan, Hubei Province, China. ${ }^{1}$ WHO declared the
Strengths and limitations of this study

- Unlike other studies, this study used selfadministered approach with COVID-19 safety precautions taken during questionnaire distribution.

- A standardised questionnaire with high validity and reliability was used in the study.

- Study provides an insight into students' knowledge and perspectives on COVID-19 preventive behaviours in reopened schools.

- Our study may be limited by social desirability bias due to self-report of the participants.

- Besides, the study could not show a cause-andeffect relationship, and the findings represent the situation during the study period.

coronavirus disease as a global pandemic on 11 March $2020 .^{2}$ The COVID-19 is affecting 219 countries and nowadays, it is a public health emergency throughout the world. ${ }^{3}$ The fast spread of the disease has taken so many lives and caused massive disruption to families, societies and economies all over the world. ${ }^{4}$ The latest statistics reveal that coronavirus has infected more than 101457202 people until 2121 January 2021, and led to the deaths of more than 2184619 people worldwide. ${ }^{3}$

The Ethiopian Minister of Health announced the first confirmed the first case of COVID-19 in Ethiopia on 13 March 2020. ${ }^{56}$ Then after the government of Ethiopia took different public health measures to prevent the spread of the disease. All primary, secondary and tertiary educational institutions across the country were closed and all public gatherings were banned, impacting more than 26 million students. Hand washing and social distancing were the main preventive measures communicated to the general public. ${ }^{78}$ On 8 April 2020, Ethiopian government declared a State of emergency to intensify the control and prevention of the spread 
of the disease. ${ }^{5}$ As of 27 January 2021, there were 134569 confirmed COVID-19 cases and 2075 deaths from the disease. $^{9}$

On 18 September, the Ethiopian Minister of Health advised Parliament that it was possible to reopen schools provided certain conditions were met. The ministry adapted the global guidance for reopening schools to make them safer and established structures to facilitate the process of reopening. ${ }^{10}$ The knowledge on mode of disease transmission, basic hygiene principles and other public health measures are important for effective control measures. ${ }^{11}$ The government of Ethiopia is using different strategies to enhance the knowledge, attitude and practices towards COVID-19 prevention measures and are not motivating the response to COVID-19. ${ }^{512}$

During such pandemic the WHO advices everybody to take responsibility and adopt protective behaviours. ${ }^{13}$ The lack of knowledge about the disease would be one of the most common driving factors for poor adoption of COVID-19 prevention measures and may increase the spread of the disease as well as the number of new cases. $^{14} 15$ Studies conducted in Ethiopian reported contradicting findings regarding knowledge and practices towards COVID-19 preventive measures among different population. ${ }^{16}$ Some reported the existence of good knowledge about COVID-19 and level of prevention practice ${ }^{17}$ while others reported poor knowledge and poor practice related to COVID-19 preventive practice. ${ }^{16-18}$ Some studies suggested to consider individuals risk perception as a major factor to promote the adherence of preventive measures. ${ }^{512} 19$

Secondary school students have poor knowledge and healthy preventive practices towards COVID-19. The exposure to education intervention had improved knowledge, attitude and practice of the students. ${ }^{20}$ On the other hand, high school students in Ghana had substantial level of knowledge and positive perception of COVID-19. ${ }^{21}$ A couple studies in Europe revealed secondary school present a good level of knowledge, shows appropriate practice and positive attitude towards COVID-19 at the time of its outbreak. ${ }^{22} 23$

The Ethiopian government is using an adopted Risk Communication and Community Engagement strategic approach to empower people to adopt preventive and health-seeking behaviours contributing to a reduction in the spread of COVID-19. ${ }^{524}$ The Ethiopian Ministry of Health and Ethiopian Public Health Institute are proactively working on disseminating prevention messages on radio and television, at federal and regional levels, reaching a potential audience of 30 million people..$^{25}$ In addition, volunteers conducted mobilisation activities against COVID-19 in marketplaces, slums and congested public places. ${ }^{26}$ However, the knowledge and practices towards COVID-19 among the public is not sufficient enough to tackle the rapidly transmitted disease and undermined the preparedness and responses in the country. ${ }^{5}$
In Ethiopia, Schools are reopening after several months of closure. As schools reopen, strict precautionary measures are in place to protect students, teachers, nonteaching staff within the school and community from COVID-19. In such case, the reopening of schools brings an opportunity to empower students as agents of change to adopt the recommended positive behaviours to prevent the spread of COVID-19. ${ }^{27}$ Improved awareness and adaption of preventive behaviours among students facilitate positive changes in the general population through health messages and observation learning. Therefore, we need to understand the magnitude of COVID-19-related knowledge and preventive practice among students in the re-opened high schools. In addition, we also assessed whether sociodemographic, social support and source of COVID-19-related information were associated with the knowledge, and preventive health behaviour towards COVID-19.

\section{METHODS}

\section{Study design and area}

An institutional-based cross-sectional study design was conducted in Gondar city from November to ${ }^{27}$ December 2020. Gondar city administration is located at about $727 \mathrm{~km}$ away from Addis Ababa, the capital city of Ethiopia, and $180 \mathrm{~km}$ away from Bahirdar the capital city of Amhara Regional State. In the city, there are 12 governments and 5 private high schools (grades 9-12) with more than 23200 students. $^{28}$

\section{Sample size and sampling procedure}

The sample size was calculated using a single population proportion formula; considering $50 \%$ (since no previous study found) proportion of students who have good preventive health practice towards COVID-19, 95\% CI, marginal error (d) of 5\% and 5\% non-response rate. The final sample size was estimated to be 403 participants. The adequacy of the sample size for identifying the predictors of COVID-19-related knowledge preventive behaviour was evaluated using power analysis.

Stratified simple random sampling technique was used to select the study participants. First, stratification was done based on school ownership into private and governmental schools. Then, four governmental (Fasiledes, Fasiledes Third, Azezo and Hidar 11) and two private secondary schools (Debreselam and Waliya) were selected on random basis. Finally, study participants were selected randomly based on their class roaster using Microsoft excel random number generator.

\section{Study variables}

Preventive health behaviours

Refers to the participant's practice concerning, hand washing, physical distancing, facemask wearing so as to prevent COVID-19 infection. It was measured by eight items having five-point response rate ranging from 1 (Never) to 5 (always). The composite score of the 
Table 1 Sociodemographic characteristics of secondary school students in Gondar city, Northwest Ethiopia, 2021 ( $\mathrm{n}=370$ )

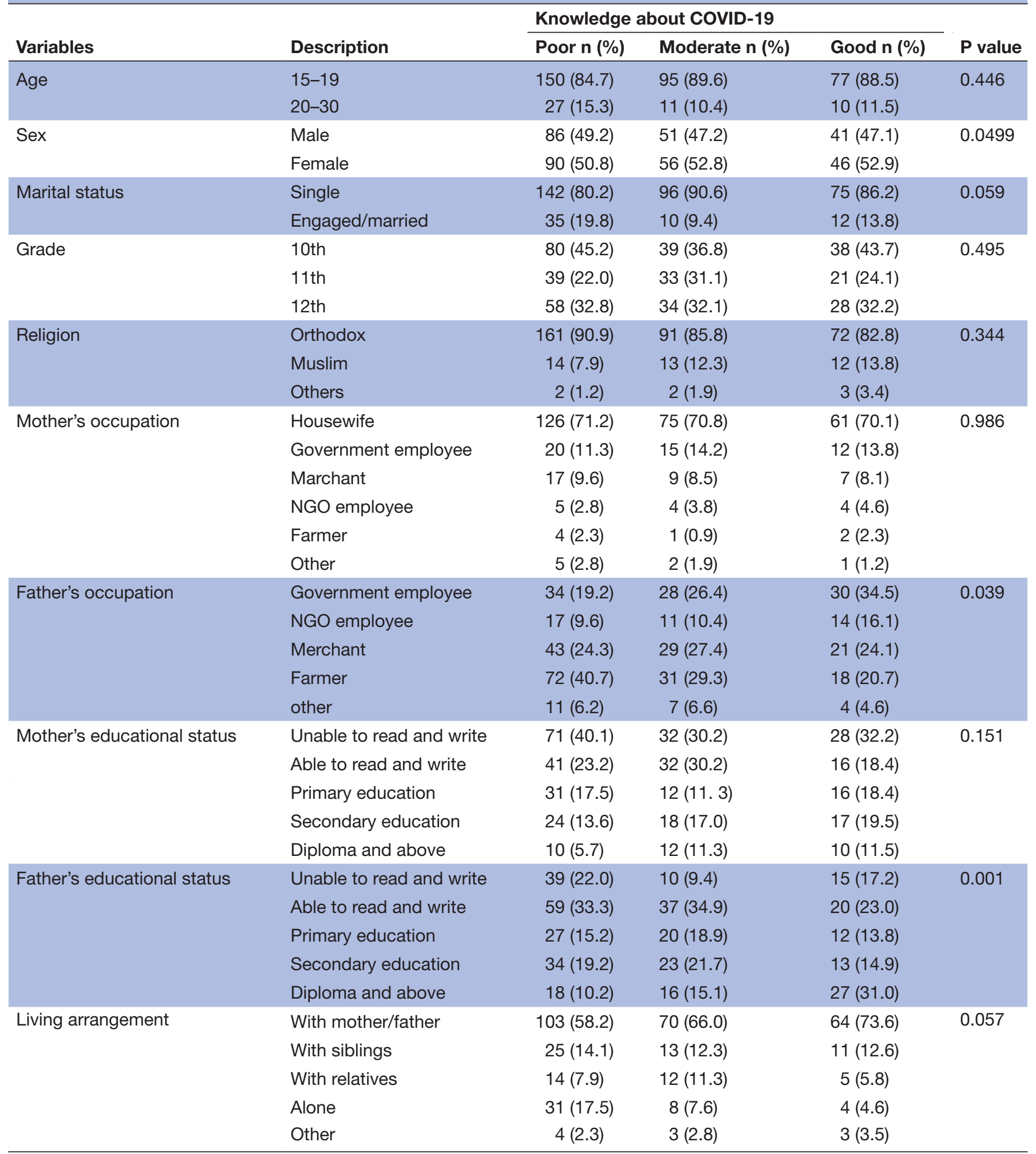

preventive behaviours ranged from 7 to 35 . The higher score indicates compliance behaviour.

Knowledge of COVID-19

Refers to participant's cognition of symptoms, nature and preventive measures of COVID-19. It was measured by 17 items having three response categories ( $1=$ true, 2=false and 3=I don't know). A correct answer was coded as 1 point whereas, the incorrect and unknown answer was recoded as zero. The composite score ranged from 0 to 17 and categorised using Bloom's cut-off point, as lowlevel of knowledge (less than 60\%; less than 12 score), moderate level of knowledge $(60 \%-80 \% ; 13-14$ score) 


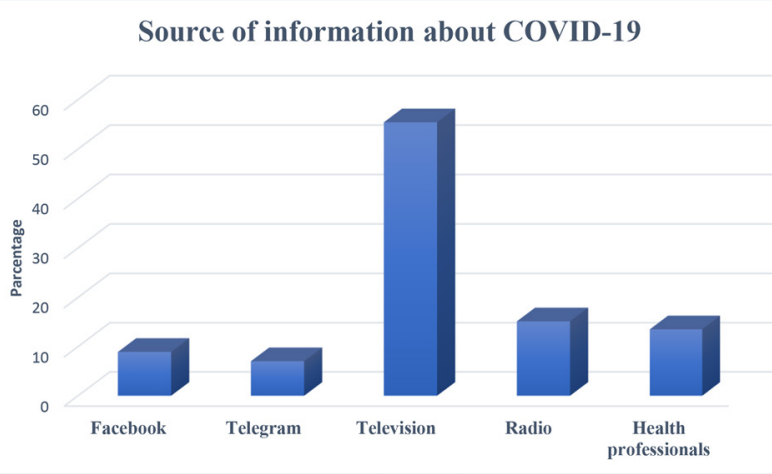

Figure 1 Source of information about COVID-19 among secondary school students in Gondar city, Northwest Ethiopia, 2021 ( $n=370)$.

and good level of knowledge $(80 \%-100 \% ; 15$ and above score). ${ }^{29}$

\section{Data collection tools and procedures}

The data were collected by using pretested selfadministered questionnaire adapted from different literatures. ${ }^{1517}$ The questionnaire was prepared in English, then translated to the local language, Amharic. Trained four BSc nurses and two Masters of public health professionals collected the data and supervised the data collection process, respectively. COVID-19 safety measures (physical distancing, wearing masks and hand hygiene) were taken during the data collection process. The questionnaire had five sections including sociodemographic, social support, source of COVID-19-related information, knowledge and preventive health behaviour. Content validity and pretest was done with six experts panel discussion and 20 students. It was determined by Item level Content Validity Index (I-CVI) of 0.78 or higher, Scale level CVI by Universal Agreement (S-CVI) 0 f 0.8 or higher and S-CVI by Average 0.9 or higher. Data collectors and supervisors took 1-day training on the objective of the study, content of the questionnaire and ethical issues need to be taken during the data collection process (see the research tool at online supplemental file).

\section{Knowledge about COVID-19}

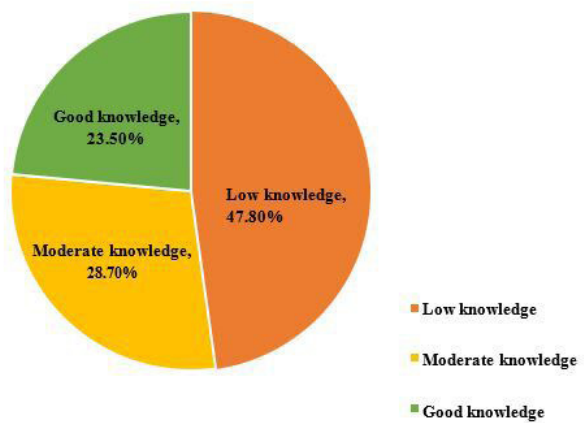

Figure 2 Knowledge status about COVID-19 among secondary school students in Gondar city, Northwest Ethiopia, 2021 ( $n=370)$.

\section{Data processing and analysis}

Each questionnaire was reviewed for completeness and consistency on daily basis. The internal consistency of the items was checked by Cronbach's alpha. The collected data entered in to EpiData V.4.6 and exported into to STATA V.14 statistical software for analysis. Multicollinearity among the independent variables was assessed using variance inflation factors and was in the acceptable range. Descriptive statistics was used to quantify the magnitude of preventive healthy behaviour, knowledge and describe the characteristic of the participant. Bivariable and multivariable ordinal logistic regression model was fitted to identify the factors associated with knowledge of COVID-19. Those variables with a $\mathrm{p}<0.25$ in the bivariable model were fitted in the multivariable model. The assumptions of ordinal logistic regression were checked using $\chi^{2}$ and parallel line tests (the model was well fitted with the data). Normality and homogeneity of variances were checked for preventive health behaviour (the variable was normally distributed). Simple linear regression analysis was computed and all independent variables with $p<0.25$ were entered in multiple linear regression. An unstandardized $\beta$ coefficient was used to interpret the effect of predictors to preventive health behaviour. Variables with $\mathrm{p}$ value less than 0.05 at $95 \%$ CI were considered as statistically significant.

\section{Patient and public involvement}

This research was done without involving patient on the design and implementation. But the participants and administrative officials were informed about study objectives. The results will be disseminated to Gondar city education office and through open access publication.

\section{RESULTS \\ Sociodemographic characteristics}

A total of 370 respondents were participated with a response rate of $91.8 \%$. The non-response was due to not replying to items on the questionnaire $(4.0 \%)$, inconsistent responses $(2.4 \%)$ and not volunteered without reason $(1.8 \%)$. More than half of the participant $(51.9 \%)$ were females. The higher proportion of the participant were affiliated with Orthodox religion (87.6\%), single $(84.6 \%)$ and live with their parents $(64.1 \%)$. The mean age of participants $18.0 \pm 1.8$ years with the minimum 15 and maximum 30 years (table 1 ). With regard to sources of information, television $(55.4 \%)$ was the most common source of information about COVID-19 (figure 1).

\section{Knowledge about COVID-19}

The reliability test of the knowledge about COVID-19 items for Cronbach's alpha was 0.79 According to the Blooms cut-off point nearly half $(47.8 \%)$ of the participant had low knowledge about COVID-19. Only one-fourth of them $(23.5 \%)$ had a good knowledge (figure 2 ). Table 2 also presents the details of knowledge about COVID-19. 
Table 2 Knowledge about COVID-19 among secondary school students in Gondar city, Northwest Ethiopia, 2021 ( N=370)

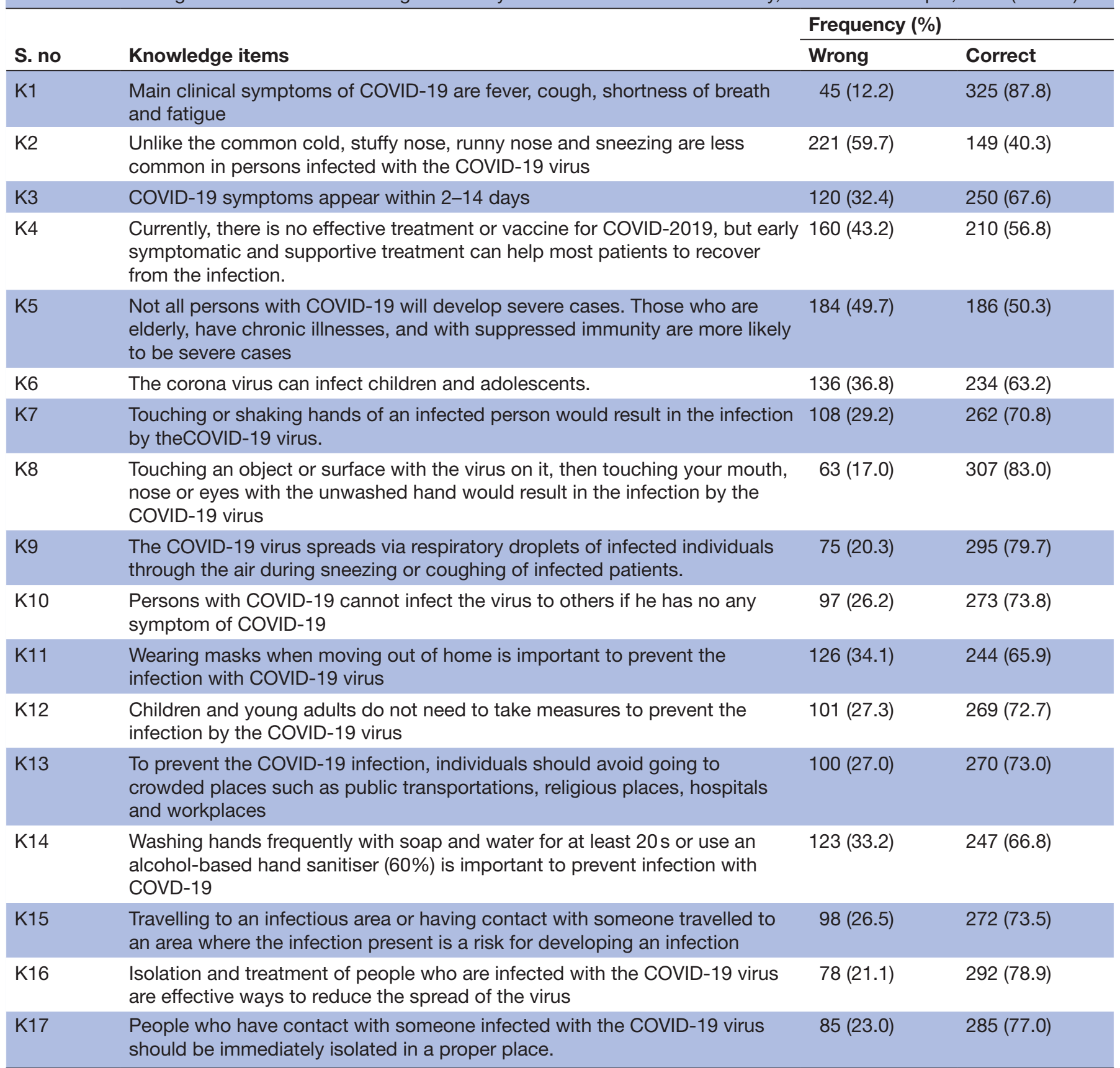

\section{Preventive health behaviour}

The reliability test of the preventive health behaviour items for Cronbach's alpha was 0.79 . The mean of preventive health behaviour was 22.8 with $\mathrm{SD}$ of 6.2 . Two hundred and four $(55.1 \%$, 95\% CI $50.0 \%$ to $60.2 \%$ ) respondents scored above the mean score of preventive health behaviour (table 3 ).

\section{Predictors of knowledge about COVID-19}

Of the variables satisfied the assumption of proportional odds model, age, marital status, religion, father's educational status, father's occupation, living arrangement and sources of information for COVID-19 were associated with knowledge of COVID-19 with a $\mathrm{p}<0.25$.
After controlling the confounding variables, marital status, religion, father's education, living arrangement and sources of information were significantly associated with knowledge about COVID-19. The result of ordinal logistic regression analysis showed that the odds of having good knowledge (verses medium or poor knowledge) were 0.47 times lower for engaged/ married students as compared with single students (adjusted OR, AOR $=0.47,95 \%$ CI $0.25,0.90$ ). The odds of having good knowledge was nearly 7.71 times higher for students affiliated with other religion as compared with those affiliated with Orthodox $(\mathrm{AOR}=1.78,95 \% \mathrm{CI}$ 1.24 to 2.55 ). Students belong to fathers with diploma 
Table 3 COVID-19 preventive behaviours among secondary school students in Gondar city, Northwest Ethiopia, 2021 ( $\mathrm{n}=370$ )

\begin{tabular}{|c|c|c|c|}
\hline S. no & Items & Mean & SD \\
\hline $\mathrm{PH} 1$ & I keep a distance of at least $2 \mathrm{~m}$ from others. & 2.66 & 1.28 \\
\hline $\mathrm{PH} 2$ & $\begin{array}{l}\text { I place a tissue paper or bending elbow in front of my mouth and nose when coughing or } \\
\text { sneezing. }\end{array}$ & 3.26 & 1.33 \\
\hline $\mathrm{PH} 3$ & I don't shake hands with others and don't kiss them. & 2.92 & 1.30 \\
\hline $\mathrm{PH} 4$ & I don't leave the house unless absolutely necessary & 2.66 & 1.32 \\
\hline $\mathrm{PH} 7$ & I wash my hands with soap and water before touching anything while entering home. & 2.98 & 1.44 \\
\hline \multirow[t]{2}{*}{ PH8 } & I wear facemask consistently whenever I go out to my home. & 2.69 & 1.39 \\
\hline & Overall preventive behaviour standard score & 2.85 & 0.77 \\
\hline
\end{tabular}

and above education were 2.56 times higher odds of good knowledge than students belong to father with no education $(\mathrm{AOR}=2.56,95 \% \mathrm{CI} 1.07$ to 6.12$)$. The odds of having good knowledge was nearly 0.32 times lower for students living alone than those who lived with their parents $(\mathrm{AOR}=0.32,95 \% \mathrm{CI} 0.15$ to 0.69$)$. Students who used television $(\mathrm{AOR}=6.68,95 \%$ CI 2.73 to 16.36$)$, radio $(\mathrm{AOR}=2.91,95 \% \mathrm{CI} 1.04$ to 8.11$)$ and health profession ( $\mathrm{AOR}=4.15,95 \%$ CI 1.51 to 11.40$)$ as sources of information on COVID-19 were 6.68, 2.91 and 4.15 times higher odds of good knowledge than those who used Facebook, respectively (table 4 ).

\section{Predictors of COVID-19 preventive health behaviours}

In simple linear regression, sex, marital status, grade level, mother's educational status, father's educational status, mother's occupation and father's occupation, living arrangement, source of information about COVID-19 and social support were significant at with a $\mathrm{p} \leq 0.25$ and entered in to multiple linear regression. In the multiple linear regression analysis, sex ( $\beta$ : $1.3595 \%$ CI 0.02 to 2.68), having father employed in non-governmental organisation (NGO) $(\beta$ : $-2.37,95 \% \mathrm{CI}-4.71$ to -0.02$)$, other jobs $(\beta$ : $-3.46,95 \%$ CI -6.49 to -0.43$)$ and health profession as source of information $(\beta: 3.00$, 95\% CI 0.20 to 5.80) were statistically significant at a $\mathrm{p}<0.05$. The standardised regression coefficient revealed that source of information was the most important predictor of adoption of COVID-19 preventive measures. The analysis of this study showed that female students were 1.35 times more frequently engaged in preventive health behaviour than males. Compared with students with father employed in government institution, engagement in COVID-19 preventive behaviour decreased by 2.37 and 3.46 times among those whose father was employed in NGO and other jobs, respectively. Students who used health professionals as sources of information were three time more engaged in preventive health behaviour than those who use Facebook as source of information provided that other variables are kept constant (table 5).

\section{DISCUSSION}

This study assessed the COVID-19-related knowledge and preventive health behaviour of the student and associated factors in the reopened schools, Northwest Ethiopia. Student's adherence to COVID-19 preventive behaviours (physical distancing, wearing a mask and hand washing) are a key to sustain the education in the pandemic era. Previous studies addressed the knowledge, attitude and practices of COVID-19 immediately after onset of the pandemics in Ethiopia. ${ }^{16-18}$ These studies revealed lack of knowledge, attitude and preventive practice among different populations. ${ }^{1619}$ Since the adherence of these behaviours reduce the spread of the disease among the students, teachers and community, the current study focused the knowledge of the student and their level of engagement in preventive behaviour.

A lack of adequate knowledge is probably the driving force for poor preventive practice as well as the spread of the disease. In this study only about half (52.2\%) of the students had at least moderate knowledge about COVID19. This study result is higher than studies done among health science student in Arbaminch ${ }^{30}$ and secondary school student in Egypt (before intervention). ${ }^{20}$ On the other hands, this finding is lower than studied done among college student in Amhara region, undergraduate student in Debre Berhan University, undergraduate medical students in Egypt, high school students in Ghana, Iranian medical students, Libya, Jordan and Portugal. $^{21-2331-36}$ The discrepancy is may be due difference in access and use of information sources. The result highlights the need to address the gap of knowledge timely using tailored and effective approaches. The authors recommended briefing sessions or including information about the disease is health-related subjects/ lessons may enhance the knowledge of the students.

This study showed students had low preventive health behaviours against COVID-19 with $55.1 \%$ respondents scored above the mean score. Contrary to scientific recommendation social distancing, hand washing, and wearing of a mask were not highly prevalent practices among students. Similar finding is reported by studies 
Table 4 Predictors of knowledge about COVID-19 among secondary school students in Gondar city, North West Ethiopia, $2021(n=370)$

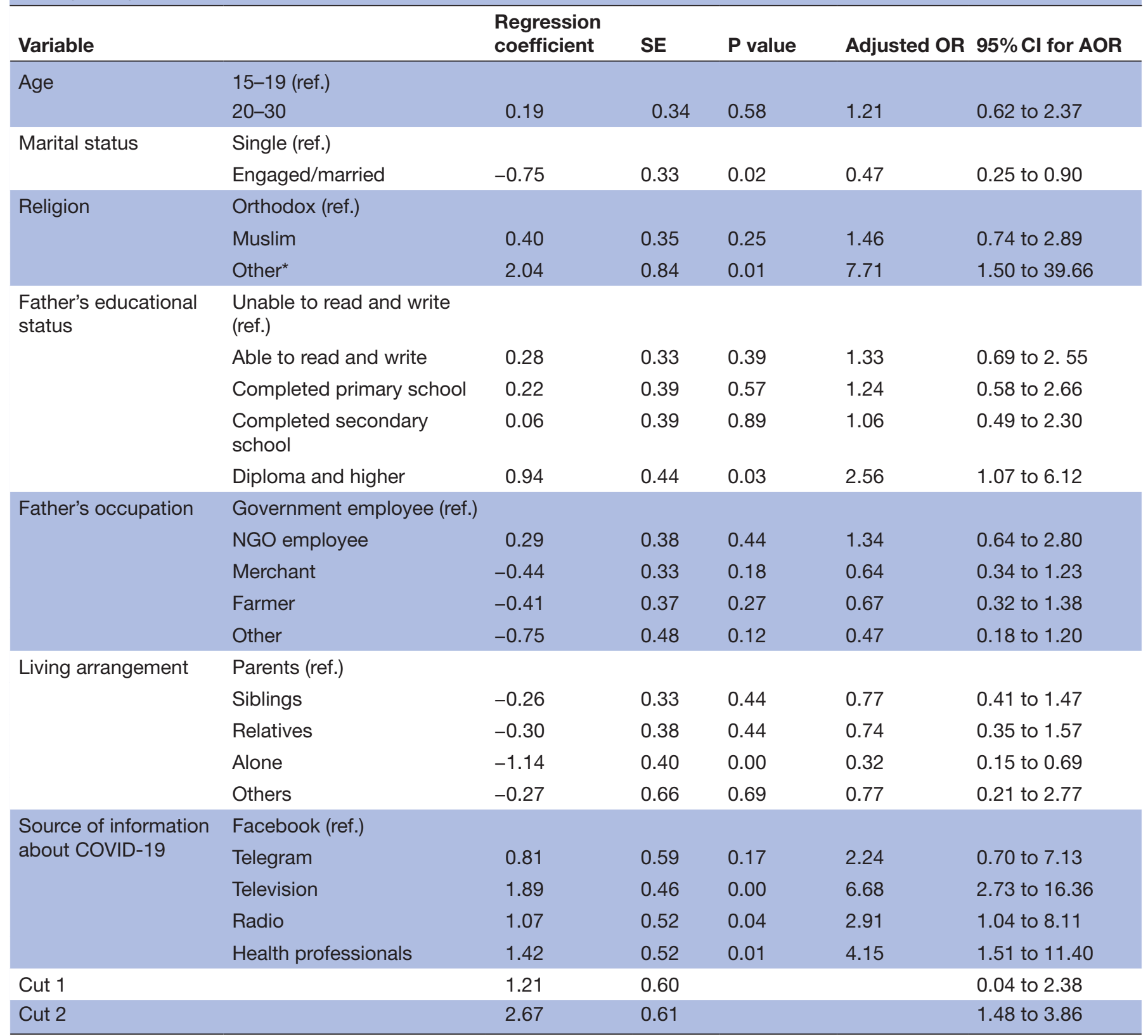

*Other: catholic and protestant.

NGO, non-governmental organisation.

done among university students in Debre Birhan university ${ }^{32}$ and secondary school student in Egypt. ${ }^{20}$ Contrary to this study among secondary school students in in Italy ${ }^{23}$ and Portugal $^{22}$ reported that students are practicing appropriate preventive behaviours. The difference may be due to difference in COVID-19-related information access, risk perception and enforcement of COVID-19related measures in nations. In addition, college student in Amhara region, medical students in Egypt, Iran, Libya, Jordan and University students in Birzeit (Palestine) ${ }^{23313335-37}$ implemented proper strategies to prevent its spread of the disease. This may be due too high-risk perception, advanced knowledge about the disease and previous experience of infection prevention practice enabled them to properly implement COVID-19 preventive health behaviour. School authorities with respected responsible health authorities need to identify, meet and coordinate the implementation of preventive behaviours at schools. The promotion and awareness creation activities also need to be revised according to the situation evolution.

The analysis of predictors of knowledge about COVID-19 revealed that engaged/married and students living alone had lower level of knowledge. Similarly, study done among college student in Amhara region reported single students had good knowledge about COVID-19. ${ }^{31}$ 
Table 5 Predictors of COVID-19 preventive health behaviours among secondary school students in Gondar city, North West Ethiopia, $2021(n=370)$

\begin{tabular}{|c|c|c|c|c|}
\hline Variable & & Unstandardised B & Standardised $\beta$ & $95 \% \mathrm{Cl}$ for $\mathrm{B}$ \\
\hline \multirow[t]{2}{*}{ Sex } & Male (ref.) & & & \\
\hline & Female & $1.35^{\star}$ & 0.11 & 0.02 to 2.68 \\
\hline \multirow[t]{2}{*}{ Age } & $15-19$ (ref.) & & & \\
\hline & $20-30$ & 0.73 & 0.04 & -1.37 to 2.82 \\
\hline \multirow[t]{2}{*}{ Marital status } & Single (ref.) & & & \\
\hline & Engaged/married & 1.64 & 0.10 & -0.18 to 3.45 \\
\hline \multirow[t]{3}{*}{ Grade } & $10^{\text {th }}$ (ref.) & & & \\
\hline & $11^{\text {th }}$ & -0.61 & -0.04 & -2.25 to 1.02 \\
\hline & $12^{\text {th }}$ & 0.17 & 0.01 & -1.42 to 1.76 \\
\hline \multirow{5}{*}{$\begin{array}{l}\text { Mother's educational } \\
\text { status }\end{array}$} & Unable to read and write (ref.) & & & \\
\hline & Able to read and write & -1.16 & -0.08 & -2.84 to 0.53 \\
\hline & Completed primary school & -0.98 & -0.06 & -3.01 to 1.04 \\
\hline & Completed secondary school & -1.33 & -0.08 & -3.67 to 1.01 \\
\hline & Diploma and higher & -1.82 & -0.08 & -5.06 to 1.41 \\
\hline \multirow{5}{*}{$\begin{array}{l}\text { Father 's educational } \\
\text { status }\end{array}$} & Unable to read and write (ref.) & & & \\
\hline & Able to read and write & 0.18 & 0.01 & -1.76 to 2.13 \\
\hline & Completed primary school & 0.46 & 0.03 & -1.89 to 2.80 \\
\hline & Completed secondary school & -0.90 & -0.06 & -3.37 to 1.55 \\
\hline & Diploma and higher & -1.20 & -0.07 & -4.22 to 1.82 \\
\hline \multirow[t]{6}{*}{ Mother's occupation } & Housewife (ref.) & & & \\
\hline & Government employee & -0.72 & -0.04 & -3.08 to 1.64 \\
\hline & Marchant & -1.17 & -0.05 & -3.57 to 1.22 \\
\hline & NGO employee & 2.14 & 0.06 & -1.45 to 5.72 \\
\hline & Farmer & 0.52 & 0.01 & -4.20 to 5.25 \\
\hline & Other & 1.07 & 0.03 & -3.32 to 5.46 \\
\hline \multirow[t]{5}{*}{ Father's occupation } & Government employee (ref.) & & & \\
\hline & NGO employee & $-2.37^{\star}$ & -0.12 & -4.71 to -0.02 \\
\hline & Merchant & -0.25 & -0.02 & -2.36 to 1.85 \\
\hline & Farmer & -0.59 & -0.04 & -2.84 to 1.67 \\
\hline & Other & $-3.46^{\star}$ & -0.13 & -6.49 to -0.43 \\
\hline \multirow[t]{5}{*}{ Living arrangement } & Parents (ref.) & & & \\
\hline & Siblings & 0.60 & 0.03 & -1.38 to 2.58 \\
\hline & Relatives & -0.53 & -0.02 & -3.00 to 1.93 \\
\hline & Alone & 0.02 & 0.01 & -2.30 to 2.26 \\
\hline & Others & 2.42 & 0.06 & -1.54 to 6.39 \\
\hline \multirow{5}{*}{$\begin{array}{l}\text { Source of information } \\
\text { about COVID-19 }\end{array}$} & Facebook (ref.) & & & \\
\hline & Telegram & -0.41 & -0.02 & -3.61 to 2.78 \\
\hline & Television & 0.92 & 0.07 & -1.41 to 3.26 \\
\hline & Radio & -0.12 & -0.01 & -2.83 to 2.60 \\
\hline & Health professionals & $3.00^{*}$ & 0.17 & 0.20 to 5.80 \\
\hline Social support & $10.32 \pm 2.30$ & 0.29 & 0.11 & -0.01 to 0.58 \\
\hline Constant & & 19.84 & & 15.16 to 24.53 \\
\hline
\end{tabular}

${ }^{*} \mathrm{P}<0.05$. 
The other study health science student in Arbaminch reported that married and student living with family members had good knowledge than their counterparts. ${ }^{30}$ Whereas, on the other hand, being affiliated with other religions, having educated father and using television, radio and health professional as a source of information were positively associated with good knowledge. Health professionals and electronic medias were the reliable source of information and promote health awareness and engagement in preventive measures. Study done in Debre Berhan University reported that source of information about COVID-19 associated with the mean knowledge. ${ }^{32}$ Elsewhere study done in Ghana reported that increased access of information from electronic media and the role of peers and family members in dissemination of COVID19-related information. ${ }^{21}$

The analysis on the predictor of preventive health behaviour among the student showed that being female and health professionals' source of information increased the engagement in preventive behaviours. Although those who had increased exposure to electronic medias seemed to be more aware of preventive measures to avoid COVID-19 spread, there is still the possibility that misinformation on the internet can have produced the opposite. We found that females engaged more in preventive health behaviours than males. This is allied with a tendency of females to be more health conscious and engaged in preventive behaviour. ${ }^{38}$ Moreover, the low preventive behaviour in men may be due to their perceptions of masculinity which reduces their motivation to accept preventive health behaviour. ${ }^{24} 39$ Similar findings were reported by studies done in Portugal, medical students in Egypt, university students in Palestine and China. ${ }^{22} 333740$ Health messages and other health promotion initiatives at schools need to introduce gender-specific tailor preventive measures in order to enhance their efficiency. On the other hand, student whose father employed in NGO and other jobs had decreased engagement in preventive health behaviours. In this study, the level of knowledge of the participant was not significant predictor for preventive health behaviour. This may be due to knowledge is neither sufficient nor necessary to trigger a behavioural change (adopting preventive behaviours).

This study has certain limitations to be noted. This is cross sectional study, could not show a cause-and-effect relationship and the findings represent the situation during the study period. The knowledge and preventive practices among the student may change rapidly. Besides, this study was based on self-report of the participant. There would be recall and social desirability that can bias the findings.

\section{CONCLUSIONS}

In this study, substantial number of the students had inadequate knowledge about COVID-19 and poorly engaged in COVID-19 preventive health behaviour. The research results indicated that engaged/married and students living alone had a lower level of knowledge. Being affiliated with other religions, having educated father, and using television, radio and health professional as a source of information were all associated with good knowledge. Sex, father occupation and source of information have all contributed to COVID-19 preventive behaviours. Therefore, the effectiveness of COVID-19 prevention measures needs to be well established among the students. Interventions that increase the awareness of the students and promote health behaviours need to be strengthen in secondary schools. It is suggested to introduce COVID19-related message need to be disseminated in related academic sessions, using school clubs and minimedias. In addition, the main sources of COVID-19-related information (health professionals, television and radio) need to strengthen the dissemination of tailored, credible and timely message to enhance the knowledge and engagement the student in preventive health behaviours.

Acknowledgements The authors would like to thank the study participant and data collectors for their cooperation.

Contributors SH, AA, AK and KS conceived and designed the study. SH, AA, AK and KS participated in data processing and management. SH analysed the data and drafted the manuscript. AK and KS participated in data analysis and interpretation. $\mathrm{SH}, \mathrm{AA}, \mathrm{AK}$ and KS reviewed the drafted manuscript. All authors read and approved the final manuscript.

Funding The authors have not declared a specific grant for this research from any funding agency in the public, commercial or not-for-profit sectors.

Competing interests None declared.

Patient consent for publication Not required.

Ethics approval Ethical clearance was obtained from the Institutional Review Board of the University of Gondar with a reference number of V/P/ RCS/05/588/2020.

Provenance and peer review Not commissioned; externally peer reviewed.

Data availability statement Data are available on reasonable request. Data will be available from the corresponding author on reasonable request.

Supplemental material This content has been supplied by the author(s). It has not been vetted by BMJ Publishing Group Limited (BMJ) and may not have been peer-reviewed. Any opinions or recommendations discussed are solely those of the author(s) and are not endorsed by BMJ. BMJ disclaims all liability and responsibility arising from any reliance placed on the content. Where the content includes any translated material, BMJ does not warrant the accuracy and reliability of the translations (including but not limited to local regulations, clinical guidelines, terminology, drug names and drug dosages), and is not responsible for any error and/or omissions arising from translation and adaptation or otherwise.

Open access This is an open access article distributed in accordance with the Creative Commons Attribution Non Commercial (CC BY-NC 4.0) license, which permits others to distribute, remix, adapt, build upon this work non-commercially, and license their derivative works on different terms, provided the original work is properly cited, appropriate credit is given, any changes made indicated, and the use is non-commercial. See: http://creativecommons.org/licenses/by-nc/4.0/.

ORCID iDs

Simegnew Handebo http://orcid.org/0000-0002-0166-5560

Ayenew Kassie http://orcid.org/0000-0003-4853-6296
REFERENCES

1 Zu ZY, Jiang MD, Xu PP, et al. Coronavirus disease 2019 (COVID-19): a perspective from China. Radiology 2020;296:E15-25.

2 World health organization. Listings of WHO's response to COVID-19. Available: https://www.who.int/news/item/29-06-2020-covid timeline [Accessed 28 Jan 2021]. 
3 Worldometers. Covid-19 coronavirus pandemic, 2020. Available: https://www.worldometers.info/coronavirus/ [Accessed 28 Jan 2021].

4 COVID-19: One year later - WHO Director-General's new year message. Available: https://www.who.int/news/item/30-12-2020covid-19-anniversary-and-looking-forward-to-2021 [Accessed 28 Jan 2021].

5 Zikargae MH. COVID-19 in Ethiopia: assessment of how the Ethiopian government has Executed administrative actions and managed risk communications and community engagement. Risk Manag Healthc Policy 2020;13:2803-10.

6 Ministry of Health and Ethiopian Public Health Institute. Ethiopia confirmed the first case of Covid-19. Available: https://www.ephi.gov. et/images/pictures/pic_2011/pic_2012/First-English-Press-release-1. pdf

7 Ministry of Education. Concept note for education sector COVID 19-Preparedness and response plan. Addis Ababa, Ethiopia, 2020.

8 Baye K. COVID-19 prevention measures in Ethiopia: current realities and prospects. Intl Food Policy Res Inst, 2020.

9 WHO health emergency Dashboard; Ethiopia. Available: https:// covid19.who.int/region/afro/country/et [Accessed 28 Jan 2021].

10 UNICEF Ethiopia. The case for safely reopening schools in Ethiopia. Available: https://www.unicef.org/ethiopia/stories/case-safelyreopening-schools-ethiopia [Accessed 28 Jan 2021].

11 Erfani A, Shahriarirad R, Ranjbar K, et al. Knowledge, attitude and practice toward the novel coronavirus (COVID-19) outbreak: a population-based survey in Iran. Bull World Health Organ 2020. [Epub ahead of print: 30 Mar 2020].

12 Geda NR, Legesse B, Kebede SW. Perceptions of risks and impacts of COVID-19 among the public in Ethiopia. Frontier: Insights, 2020.

13 World Health Organization. Managing epidemics: key facts about major deadly diseases. World Health Organization;, 2018. Available: https://apps.who.int/iris/handle/10665/272442

14 World Health Organization. RCCE ACTION PLAN GUIDANCE: COVID-19 preparedness \& response. Available: https://www. who. int/docs/default-source/coronaviruse/covid19-rcce-guidance-finalbrand.pdf

15 Zegarra-Valdivia J, Vilca BN, Guerrero RJ. Knowledge, perception and attitudes in regard to COVID-19 pandemic in Peruvian population 2020.

16 Teferi SC. A review on knowledge, attitude, and practice during the COVID-19 pandemic in Ethiopia. Int J Virol Infect Dis 2020;5:040-4

17 Kebede $Y$, Yitayih Y, Birhanu Z, et al. Knowledge, perceptions and preventive practices towards COVID-19 early in the outbreak among Jimma University medical center visitors, Southwest Ethiopia. PLOS One 2020;15:e0233744

18 Tesfaye ZT, Yismaw MB, Negash Z, et al. COVID-19-related knowledge, attitude and practice among hospital and community pharmacists in Addis Ababa, Ethiopia. Integr Pharm Res Pract 2020;9:105-12.

19 Girma S, Agenagnew L, Beressa G, et al. Risk perception and precautionary health behavior toward COVID-19 among health professionals working in selected public university hospitals in Ethiopia. PLoS One 2020;15:e0241101.

20 Ayed MM, Mahmoud TM, Kamal FE. Impact of teaching program regarding COVID-19 on knowledge, attitudes, practices among student.

21 IBk L, Apanga PA, Kumbeni MT. Knowledge and perceptions on COVID-19 among senior high school students in Ghana: a crosssectional study. medRxiv 2020
22 Alves RF, Samorinha C, Precioso J. Knowledge, attitudes and preventive behaviors toward COVID-19: a study among higher education students in Portugal. JHR 2020;ahead-of-print.

23 Souli D, Dilucca M. Knowledge, attitude and practice of secondary school students toward COVID-19 epidemic in Italy: a cross selectional study. bioRxiv 2020.

24 Ministry of Health and Ethiopian Public Health Institute. Risk communication and community engagement strategy for COVID-19 outbreak response in Ethiopia. RCCE. Addis Ababa, Ethiopia: $\mathrm{MoH} \&$ EPHI, 2020.

25 UNICEF. Creating awareness about COVID-19 in Ethiopia. Available: https://www.unicef.org/ethiopia/media/2716/file/COVID\%2019\% 20Response\%20update\%20\#1.pdf

26 UNICEF Ethiopia. Available: https://www.unicef.org/ethiopia/stories/ youth-volunteers-take-streets-mobilize-against-covid-19-ethiopia-0 [Accessed 28 Jan 2021].

27 World Health Organization. Ethiopia. news and press release. Available: https://www.who.int/emergencies/diseases/novelcoronavirus-2019/advice [Accessed 28 Jan 2021].

28 Gorndar City adminstration educational Affairs, preparatory school students list by sex and school type, 2019/2020.

29 Bloom BS. Taxonomy education. New York: David McKay, 1956.

30 Wogayehu B, Taye W, Faraja K. Knowledge regarding 2019 novel coronavirus (2019-nCoV) infection among final year health science students at Arbaminch College of health sciences, southern Ethiopia: a cross-sectional study.

31 Tadesse AW, Melese N, Eshetie S. Knowledge, attitude, and practice and associated factors towards COVID-19 among college students in Amhara region, Ethiopia; a cross-sectional study.

32 Aynalem YA, Akalu TY, Gebresellassie B, et al. Assessment of undergraduate student knowledge, practices, and attitude towards COVID-19 in. Ethiopia: Debre Berhan University.

33 Soltan EM, El-Zoghby SM, Salama HM. Knowledge, risk perception, and preventive behaviors related to COVID-19 pandemic among undergraduate medical students in Egypt. SN Compr Clin Med 2020;2:2568-75.

34 Taghrir MH, Borazjani R, Shiraly R. COVID-19 and Iranian medical students; a survey on their related-knowledge, preventive behaviors and risk perception. Arch Iran Med 2020;23:249-54.

35 Elhadi M, Msherghi A, Alsoufi A, et al. Knowledge, preventive behavior and risk perception regarding COVID-19: a self-reported study on college students. Pan Afr Med J 2020;35

36 Khasawneh Al, Humeidan AA, Alsulaiman JW, et al. Medical students and COVID-19: knowledge, attitudes, and precautionary measures. A descriptive study from Jordan. Front Public Health 2020;8:253

37 Naseef HA, Hadba LS, Humos LA. Knowledge, attitudes and practices about coronavirus disease (COVID-19) among Birzeit university students: a cross-sectional study.

38 Hiller J, Schatz K, Drexler H. Gender influence on health and risk behavior in primary prevention: a systematic review. $Z$ Gesundh Wiss 2017;25:339-49.

39 Vaidya V, Partha G, Karmakar M. Gender differences in utilization of preventive care services in the United States. J Womens Health 2012;21:140-5.

40 Peng Y, Pei C, Zheng Y, et al. Knowledge, attitude and practice associated with COVID-19 among university students: a crosssectional survey in China. 